spinners of marxist fairy tales for showing how Haeckel's speculations were at odds with the chief trends in biological science.

That last bit of polemics is more revealing than Ghiselin intended. Coleman, who was president of the history of science society until his death from leukaemia last year, was as far as one can imagine from any form of confessional marxism, and equally far from the habit of using 'marxist' as a dismissive epithet rather than an eponym, like 'darwinian', for one of the most important trends in modern thought. As for fairy tales in place of painful reality, one must ask why Ghiselin is so anxious to rescue Haeckel from his reputation as an irresponsible spinner of evolutionary explanations for everything. Coleman and Allen annoyed Ghiselin by showing how comparative embryology was pushed aside by experimental embryology at the turn of the century, with far more serious consequences than the decline of esteem for Haeckel. What Ghiselin angrily calls "nonhistorical, experimentalist ideology" gathered force in departments of biology until the very existence of evolutionary studies was threatened. Ghiselin has reason to feel dismayed, but hardly to jump on the historians who have told what happened, especially not on such scholars as Coleman and Allen. Their histories of biology are as respectful as he is of systematics and evolutionary studies, including comparative embryology. Once again, Ghiselin fails to engage in polemics with biologists who promote molecular reductionism, and vents spleen on individuals who are actually his comrades on fundamental issues.

As an historian of left-wing movements, I see here a depressingly familiar pattern. When the left is in greatest peril, pressed towards extinction through declining numbers, internal squabbling begins to prevail over the criticism of power that is the left's reason for being. Ghiselin will no doubt be startled to find himself identified with the left, if only in the little world of biologists. I intend this as a compliment, and I offer as conclusive evidence his praise for "The Commoditization of Science" by Lewontin and Levins. (See their collection of marxist essays. The Dialectical Biologist.) Indeed, I would endorse his praise of that essay, which lays out the main problem that bothers Ghiselin, and does so more effectively.

Let me state the problem as I perceive it. Modern society, whether in its capitalist or its socialist forms, tends to change scientific research into the production of commodities for sale rather than the quest for truthful knowledge, not to speak of wisdom. Different strata of scientists have been affected in different degrees, as Lewontin and Levins effectively point out. (Ghiselin's alternative description of the strata - rascals, fools, hypocrites, liars and honest souls - is less useful.) Although most US scientists are directly involved in commodity production, working either as hired hands or as bosses in the service of profit rather than truth, a minority cling to the intellectual autonomy of the traditional artisan or the traditional client of royal patrons. But intellectual autonomy tends to be undermined even within that minority by several forces, the most obvious of which is the bureaucratization of patronage, that is, the modern system of grant-getting. It tends to reward those who seek to satisfy a bureaucratic hierarchy, rather than those who seek truth, not to speak of wisdom.

I have deliberately injected troublesome concepts - intellectual autonomy, truth, wisdom - for a life in science is supposed to approach those priceless goals, and the effort to discuss basic problems of science without reference to them confuses rather than clarifies the issues. Nor can the discussion be limited to abstract philosophical analysis. Anxiety about the commoditization of science is part of a pervasive worry in all areas of modern life. Modernity requires and at the same time rebukes the autonomous mind, the self that would truly know how it stands in relation to the world at large.

\section{Round in circles}

\section{Lee A. Segel}

Free Energy Transduction and Blochemical Cycle Kinetics. By Terrell L. Hill. SpringerVerlag: 1989. Pp.119. Pbk 119.

ThermodynAmics is a difficult subject for many scientists, including myself. The difficulty lies in the fact that thorough understanding requires full intuitive appreciation of macroscopic entities (such as entropy and various forms of free energy) and their relationships. Yet these relationships can only be derived in an entirely convincing fashion by probabilistic analysis of underlying kinetic models. The subtlety of the analysis required is attested to by the continuing generation of important new results, even for what seem superficially to be relatively simple situations.

For decades, Terrell Hill has been a major figure in such 'thermostatistical' research (although ugly, 'energo-statistical' might be a better neologism, for at least in the biological sciences energy transduction and dissipation often lie at the centre of attention, not temperature changes). The book under review is essentially an abridged, simplified and updated version of his Free Energy Transduction in Biology (Academic, 1977), which in turn was primarily a distillation of his own research. The present title is more accurate, for a considerable amount of material on cycle
Variations on that theme appear not only in The Communist Manifesto, where Lewontin and Levins found it, but also in Spinoza and Rousseau and Schiller, where Marx found it. A roll-call of famous thinkers who have developed striking versions of it would be impossibly long.

Let me note merely that scientists are quite mistaken if they regard this as a problem only for philosophers or imaginative writers. When Einstein declared that most scientists are imprisoned in the "traditions of the herd" (see EinsteinBorn Briefwechsel 203 (1969)) by their training in "mechanized and specialized thinking", he was echoing the Nietzschean version of the anxious theme. It is far too complex to be dealt with adequately here, but it needs to be mentioned, for the greatest deficiency of Ghiselin's book is its unawareness of the tradition within which his questing mind is thrashing about. I urge him to read Max Weber's great lecture, "Science as a Vocation", to get a sense of the tensions that moved him to write this book.

David Joravsky is in the Department of History, Northwestern University College of Arts and Sciences, Evanston, IIIinois 60208, USA, and is the author of Russian Psychology: A Critical History to be published by Basil Blackwell.

kinetics is included. All but the simplest biochemical reaction schemes contain cycles (with accompanying constraints imposed by the requirement of microscopic reversibility).

The basic model treated consists of a number of discrete states with assigned constant transition probabilities per unit time between every pair of states, in both directions. The model can be represented by a diagram (or 'graph' in the more modern mathematical sense) consisting of vertices corresponding to the states and arrows corresponding to the transitions allowed. Many important problems arise, such as determining efficient and intuitively satisfying ways to calculate the rate at which a given cycle on the diagram is traversed, or the mean number of cycles before a final absorbing state is attained. These matters are purely probabilistic. Thermodynamics enters when freeenergy levels are calculated for the various states, and fluxes are related to forces that are proportional to differences in free energy.

The book is clearly written, with a commendable plan of illustrating concepts by detailed treatment of carefully selected examples. Although no exercises are provided, this slim and interesting volume indeed fulfils its goal "to be a textbook for a class or for self-study".

Lee A. Segel is in the Department of Applied Mathematics and Computer Science, Weizmann Institute, Rehovot, Israel. 